\title{
COMPARISON OF TRANSCUTANEOUS BILIRUBINOMETER READING WITH SERUM BILIRUBIN LEVEL IN EVALUATING JAUNDICE IN NEWBORN MORE THAN 32 WEEKS GESTATION- A DIAGNOSTIC TEST EVALUATION
}

\author{
Jayaram Sankar K. R1, C. Jayakumar², Anupama S. Pillai ${ }^{3}$, Jose $O^{4}$ \\ ${ }^{1}$ Assistant Professor, Department of Paediatrics, Government T. D. Medical College, Alappuzha. \\ ${ }^{2} \mathrm{HOD}$, Department of Paediatrics, Government T. D. Medical College, Alappuzha. \\ 3 Junior Resident, Department of Paediatrics, Government T. D. Medical College, Alappuzha. \\ ${ }^{4}$ Assistant Professor, Department of Paediatrics, Government T. D. Medical College, Alappuzha.
}

ABSTRACT

\section{BACKGROUND}

Objectives- 1). To assess the correlation between Transcutaneous Bilirubinometer readings (TCB) at the sternum with Total Serum Bilirubin (TSB) levels in evaluating jaundice in newborns $>32$ weeks of gestation cared in the Newborn nursery at Govt. T. D. Medical College, Alappuzha, during a period of 1 year. 2). To assess the correlation between Transcutaneous Bilirubinometer readings at different sites (Forehead, sternum and pubic symphysis) with serum bilirubin levels.

\section{MATERIALS AND METHODS}

160 babies $>32$ weeks of gestation cared in the newborn nursery of Govt. T.D. Medical College Alappuzha, with clinical jaundice at least up to thighs were selected for the study. Infants with icterus from zone 3 onwards were selected. Sick babies, babies born through meconium stained amniotic fluid, babies with hepatic dysfunction and congenital anomalies were excluded. Transcutaneous bilirubinometry was done at forehead, sternum and pubic symphysis. Blood for total serum bilirubin was taken within 10 minutes of performing transcutaneous bilirubinometry.

\section{RESULTS}

There is a positive correlation between TCB (at sternum) with serum TSB ( $r=0.669, \mathrm{p}$ value $<0.001$ ). The linear regression equation is $\mathrm{TCB}=6.371+(0.581 \mathrm{X}$ TSB$)$. Maximum correlation is found between TCB values at forehead $(\mathrm{r}=0.722, \mathrm{p}$ value $<0.001)$ and TSB values compared to those at sternum $(r=0.669)$ and pubic symphysis $(r=0.591)$. Positive correlation between entire range of TCB with TSB was also found, but was maximum when TSB is $<10 \mathrm{mg} / \mathrm{dL}(\mathrm{r}=0.625)$. The sensitivity and specificity of TCB is $80.7 \%$ and $79.6 \%$, respectively.

\section{CONCLUSION}

Transcutaneous bilirubinometer can be used as a screening tool for non-invasive assessment of neonatal jaundice. The best site for transcutaneous bilirubinometry is forehead.

\section{KEYWORDS}

Transcutaneous Bilirubinometer, Serum Bilirubin, Correlation, Newborns, Jaundice.

HOW TO CITE THIS ARTICLE: Sankar JKR, Jayakumar C, Pillai AS, et al. Comparison of transcutaneous bilirubinometer reading with serum bilirubin level in evaluating jaundice in newborn more than 32 weeks gestation- a diagnostic test evaluation. J. Evolution Med. Dent. Sci. 2017;6(35):2874-2878, DOI: 10.14260/Jemds/2017/620

\section{BACKGROUND \\ Neonatal jaundice occurs in nearly $60 \%$ of term and $70 \%$ - $80 \%$ of preterm infants and in most cases is the result of physiological process, which is harmless and self-limiting.(1) In some cases, however, very high bilirubin levels in blood can cause Bilirubin-Induced Neurological Damage (BIND) with long-term neurological sequelae known as kernicterus.(2) Quickly rising or high bilirubin levels or marked jaundice developing within 24 hours after birth warrant investigation of causative pathology such as}

Financial or Other, Competing Interest: None.

Submission 26-03-2017, Peer Review 19-04-2017,

Acceptance 25-04-2017, Published 01-05-2017.

Corresponding Author:

Dr. Jayaram Sankar K. R,

Assistant Professor,

Department of Paediatrics,

Government TD Medical College,

Alappuzha, Kerala, India.

E-mail: jayaramsankarkrdr@gmail.com

DOI: $10.14260 /$ jemds $/ 2017 / 620$ isoimmune haemolysis (ABO and $\mathrm{Rh}$ incompatibility, congenital haemolytic disease) or bile duct disorders. Phototherapy is usually sufficient to decrease serum bilirubin levels, but in severe cases exchange transfusion might be necessary. (3)

Visual inspection of the skin, sclera and mucous membranes and rough estimation of serum bilirubin levels using Kramer(4) index is a rapid and non-expensive method. Estimation of craniocaudal progression of jaundice by this method gives an indication about increasing hyperbilirubinaemia. But this method is frequently inaccurate, especially when applied to newborns of diverse racial backgrounds. (1)

The gold standard for detecting hyperbilirubinaemia is by measuring serum TSB.(5) Laboratory based measurements of bilirubin involves diazo based chemical method, direct spectrophotometric method, high performance liquid chromatographic method, colorimetric method, etc.(6) Laboratory testing of serum TSB has become one of the most common reasons for drawing blood in the newborn period.(2) This cause pain and trauma to the neonate with possibility of 
local infection and sometimes osteomyelitis.(7) Parental distress and increase in medical care costs can also result from this. Lab estimation of TSB levels is laborious and time consuming. Inter and intra laboratory variability in value of TSB may sometime interfere with decision making about management. Healthcare workers are also exposed to the risk of needle stick injury with neonatal blood sampling.(8)

These problems have led to the search for a non-invasive and reliable technique for detection of hyperbilirubinaemia and resulted in introduction of transcutaneous bilirubinometer. These meters work according to the principle of spectrophotometry. ${ }^{(8)}$ They analyse the spectrum of optical signal reflected from the subcutaneous tissues. These optical signals are converted to electrical signal by a photocell. These are analysed by a microprocessor to generate a bilirubin value on an LCD (Liquid Crystal Display). Each transcutaneous bilirubinometer have a different operating procedure, the basic principle remaining the same. The optic head of the meter is gently pressed against the neonate's skin. For correct measurement, it should make full contact with the skin and there should not be any gap between the optic head and the skin. Usually performed sites are forehead, upper end of sternum and abdomen.( ${ }^{(9)}$ Measurements against bruises, birthmarks, subcutaneous haematoma and hyperaemic areas should be avoided.

Ninety-nine percentage of what is measured by transcutaneous bilirubinometer is the bilirubin in the extravascular tissue and not in the blood vessels and hence is not a direct measurement of total serum bilirubin. Because Transcutaneous Bilirubin (TCB) is a measurement of tissue bilirubin, it might be a better predictor of kernicterus.(10) TCB readings provide immediate result. It decreases pain and discomfort for the newborn, parental distress and health costs. But one of the limitations in using TCB is that it cannot be used once phototherapy is started.

TCB can be used as a screening tool to identify infants at high risk for severe hyperbilirubinaemia by plotting obtained values on an hour specific bilirubin nomogram. TCB is a screening tool and can underestimate the TSB. Total serum bilirubin is usually checked when,(11) 1 . TCB exceeds the 70 percentile of the TSB level recommended for phototherapy; 2 . TCB exceeds the 75 percentile on the Bhutani nomogram; 3 . At followup after discharge if the TCB is $>13 \mathrm{mg} / \mathrm{dL}$. TCB monitoring is unreliable after phototherapy has begun due to bleaching of skin. It reduces the number of invasive blood tests.

Through this study, our aim was to find out whether TCB readings are comparable with serum total bilirubin concentration and to find out the best site for measurement of transcutaneous bilirubin that shows maximum correlation with serum bilirubin.

\section{MATERIALS AND METHODS \\ Study Design}

Diagnostic test evaluation.

\section{Setting}

New born nursery (IBN and OBN) of Department of Govt. TDMC, Alappuzha.

\section{Aims and Objectives}

1. To assess the correlation between transcutaneous bilirubinometer readings at the sternum with total serum bilirubin levels in evaluating jaundice in newborns more than 32 weeks of gestation cared in the Newborn nursery at Govt. T. D. Medical College, Alappuzha.

2. To assess the correlation between transcutaneous bilirubinometer readings at different sites (Forehead, sternum and pubic symphysis) with serum bilirubin levels and to determine the diagnostic value of transcutaneous bilirubinometer in evaluating pathologic jaundice by calculating sensitivity, specificity, positive predictive value and negative predictive value.

\section{Study Period}

Jan 2014 to Dec 2014 (1 Year).

\section{Sample Size}

All babies admitted to newborn nursery who met the inclusion criteria were considered for this study during a one year period from Jan 2014 - Dec 2014.

\section{Inclusion Criteria}

Newborns > 32 weeks gestation from birth to 120 postnatal hours with clinical jaundice at least up to thighs.

\section{Exclusion Criteria}

Very sick babies, babies given phototherapy, babies with congenital anomalies, chromosomal anomalies, babies with hepatic dysfunction, babies born through meconium stained amniotic fluid and babies of parents not willing to give consent.

Study was conducted after getting Institute's Ethical Committee clearance. The study procedure was explained to the mother and written consent was obtained. They were given all right to withdraw from the study when they wished. All investigations were done free of cost in our Institute itself.

\section{Instrument}

Present study was done using a new generation transcutaneous spectral reflectance meter named Drager, which gives bilirubin value in $\mathrm{mg} / \mathrm{dL}$.

Out of the 184 babies enrolled for the study, only 160 babies with clinical jaundice at least up to thighs were selected.

The study procedure was explained to the mother. A written and informed consent was obtained. Clinically, jaundice was evaluated by Kramer index. Infants with jaundice from zone 3 onwards were selected. This was done in ambient day light. Detailed history and appropriate physical examination was done. Details like name, age in hours, birth weight, gestational age, mode of delivery, perinatal complications and blood groups of mothers and babies were taken from the birth records.

Blood for total serum bilirubin was taken within 10 minutes of performing transcutaneous bilirubinometry. TSB was estimated by Vanden Berg method. This is a method by which bilirubin reacts with diazotised sulphanilic acid to produce azobilirubin (Violet colour). DMSO (Dimethyl sulphoxide) catalyses the reaction.

\section{Statistical Analysis}

Data were analysed using computer software, Statistical Package for Social Sciences (SPSS) version 16. Data entered 
into Microsoft Excel spread sheet. Correlation between TCB (at sternum) and TSB assessed using Pearson linear regression analysis to get an ' $r$ ' value. Transcutaneous bilirubinometer reading from forehead, sternum and pubic symphysis were compared separately with serum bilirubin level. Comparison of TCB at different sites and ranges with TSB was done by Bland-Altman analysis.(12)

\section{RESULTS}

Out of a total of 184 babies enrolled in the study, 24 babies were excluded (very sick babies- 7, congenital anomalies- 5 , babies born through MSAF- 6, babies received phototherapy2 , not given consent- 4).

The babies in the study ranged from 34 weeks to 40 weeks +3 days of gestational age. Mean birth weight was $2.91 \pm 0.44 \mathrm{~kg}$ ranging from $2 \mathrm{~kg}$ to $4 \mathrm{~kg}$. Mean postnatal age being $62.1 \pm 27.5$ hours, ranging from 20 hours to 120 hours. There was a slight male preponderance, M:F being 1.2:1. Majority of babies had icterus up to Kramer zone 4 (53.7\%). TSB ranged from $4.1 \mathrm{mg} / \mathrm{dL}$ to $22.3 \mathrm{mg} / \mathrm{dL}$ compared to TCB values ranging from $5.6 \mathrm{mg} / \mathrm{dL}$ to $19.8 \mathrm{mg} / \mathrm{dL}$. Mean TCB value was $13.92 \pm 2.89 \mathrm{mg} / \mathrm{dL}$ and mean TSB $12.98 \pm 3.32$ $\mathrm{mg} / \mathrm{dL}$. Mean difference of the pairs (TCB - TSB) was $1.02 \pm$ $2.33 \mathrm{mg} / \mathrm{dL}$ (Ranging from- 6.5 to 6.1 ).

\begin{tabular}{|c|c|}
\hline Clinical Variables & Distribution and Mean \\
\hline Gestational age of baby & $34 \mathrm{wks}-40 \mathrm{wks}+3$ days \\
Post-natal age & 20 Hrs $-120 \mathrm{Hrs}$ (Mean=62.1 hrs) \\
Birth weight & $2.0-4.0 \mathrm{~kg}($ Mean $=2.91)$ \\
Male: Female & $1.2: 1$ \\
TCB & $5.6-19.8 \mathrm{mg} / \mathrm{dL}(\mathrm{Mean}=13.92)$ \\
TSB & $4.1-22.3 \mathrm{mg} / \mathrm{dL}(\mathrm{Mean}=12.98)$ \\
TCB - TSB & -6.5 to 6.1 (Mean=1.02) \\
\hline \multicolumn{2}{|c|}{ Table 1. Baseline Characteristics of Study Population } \\
\hline
\end{tabular}

TSB- Total Serum Bilirubin, TCB- Transcutaneous Bilirubin.

There is a positive correlation between TCB (at sternum) with TSB $(\mathrm{r}=0.669, \mathrm{p}$ value $<0.001)$. The linear regression equation is $\mathrm{TCB}=6.371+(0.581 \mathrm{x}$ TSB $)$. Maximum correlation is found between TCB values at forehead $(\mathrm{r}=0.722$, $\mathrm{p}$ value $<$ 0.001 ) and TSB values compared to those at sternum ( $\mathrm{r}=$ $0.669)$ and pubic symphysis ( $r=0.591)$.

We found a positive correlation between TCB and entire range of TSB. But the correlation was maximum ( $\mathrm{r}=0.625)$ for TB $<10$. For TB $10-15$, ' $r$ ' value is 0.421 and for TB $>15$ ' $r$ ' value is 0.231 . Sensitivity, specificity, PPV and NPV of TCB in detecting pathological jaundice was also calculated and found to be $80.7 \%, 79.6 \%, 68.6 \%$ and $88.1 \%$ respectively.

\begin{tabular}{|c|c|c|}
\hline $\begin{array}{c}\text { Correlation } \\
\text { of TSB }\end{array}$ & $\begin{array}{c}\text { Pearson } \\
\text { Correlation- } \mathbf{r}\end{array}$ & $\mathbf{P}$ \\
\hline TCB Forehead & $.722^{* *}$ & $<0.001$ \\
\hline TCB Sternum & $.669^{* *}$ & $<0.001$ \\
\hline $\begin{array}{c}\text { TCB Pubic } \\
\text { Symphysis }\end{array}$ & $.591^{* *}$ & $<0.001$ \\
\hline \multicolumn{2}{|c|}{ Table 2. Correlation Coefficient of TCB with TSB } \\
\hline
\end{tabular}

Correlation is significant at 0.01. A strong positive correlation was found between TSB values and TCB values at all the 3 sites with maximum correlation with values at the forehead.

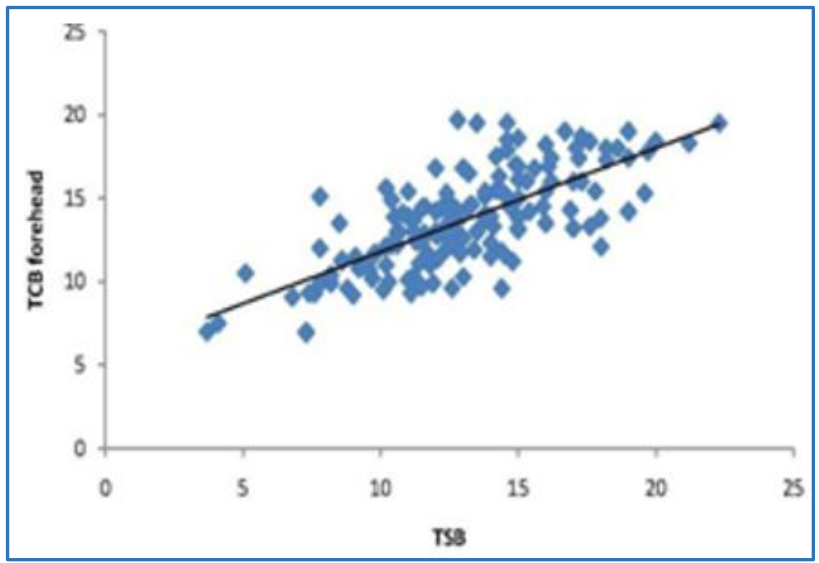

Figure 1. Bland-Altman Analysis (Forehead TCB with TSB)

Bland- Altman analysis showing linear relationship between TCB at forehead with TSB

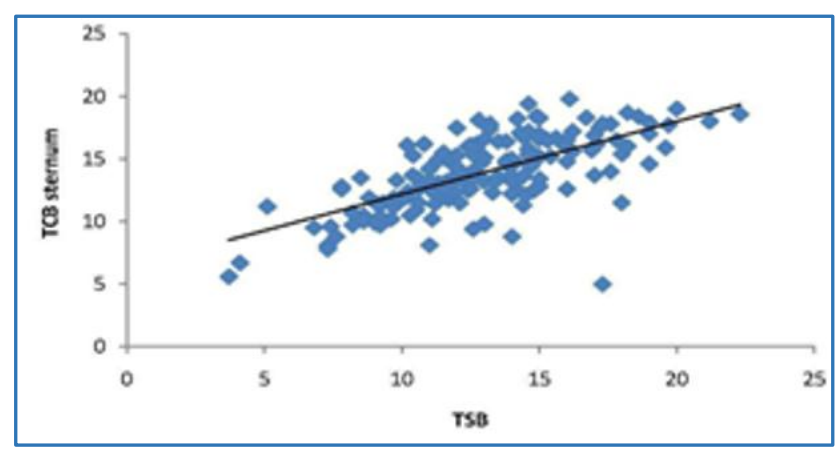

Figure 2. Bland-Altman Analysis (Sternal TCB with TSB)

Bland- Altman analysis showing linear relationship between TCB at sternum with TSB.

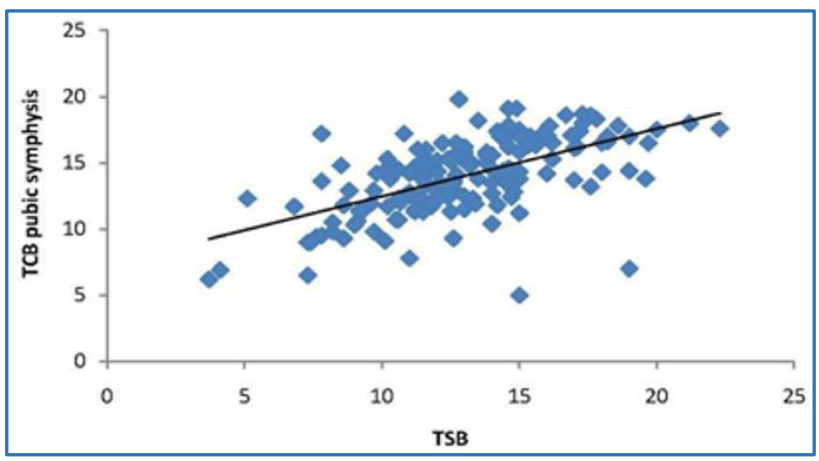

Figure 3. Bland-Altman Analysis (Symphysis Pubis TCB with TSB)

Bland-Altman analysis showing linear relationship between TCB at symphysis pubis with TSB. 


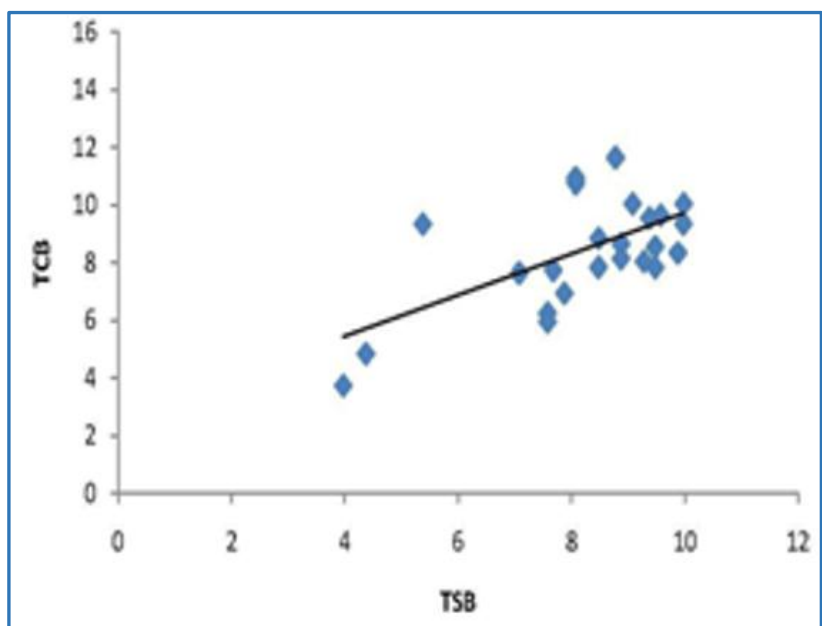

Figure 4. Bland-Altman Analysis

(TCB with $T S B<10 \mathrm{mg} / \mathrm{dL}$ )

Bland-Altman analysis showing linear correlation between TCB and TSB $<10 \mathrm{mg} / \mathrm{dL}$.

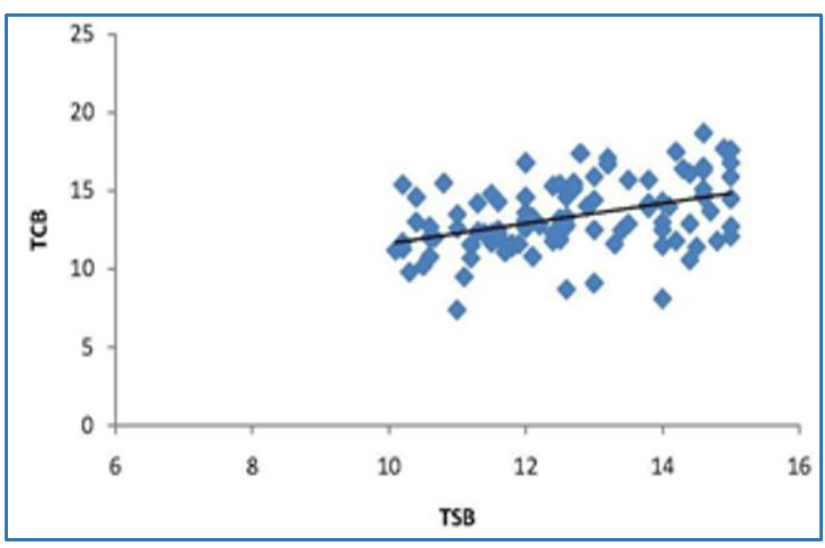

Figure 5. Bland-Altman Analysis

(TCB with TSB 10 - $15 \mathrm{mg} / \mathrm{dL}$ )

Bland-Altman analysis showing linear correlation between TCB and TSB $10-15 \mathrm{mg} / \mathrm{dL}$.

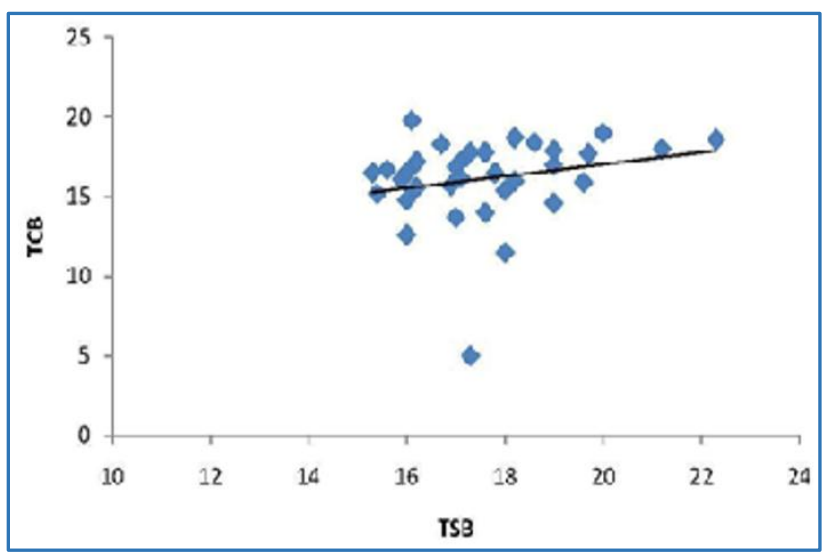

Figure 6. Bland-Altman Analysis

( $T C B$ with $T S B>15 \mathrm{mg} / \mathrm{dL}$ )

Bland-Altman analysis showing linear correlation between TCB and TSB $>15 \mathrm{mg} / \mathrm{dL}$.

\begin{tabular}{|c|c|c|c|c|}
\hline & \multicolumn{3}{|c|}{ Pathological Jaundice } \\
\hline & & Positive & Negative & Total \\
\hline \multirow[t]{2}{*}{ TCB } & Positive & 46 & 21 & 67 \\
\hline & Negative & 11 & 82 & 93 \\
\hline Total & & 57 & 103 & 160 \\
\hline
\end{tabular}

Sensitivity $=80.7 \%$, Specificity $=79.6 \%$, positive predictive value $=68.6 \%$, negative predictive value $=88.1 \%$.

\section{DISCUSSION}

Neonatal jaundice occurs in $60 \%$ term and $70 \%-80 \%$ preterm infants and is mostly physiological. Gold standard for detecting hyperbilirubinaemia is by estimating TSB, which is time consuming, painful and show inter laboratory variation. Present study showed a significant positive correlation between TSB and Transcutaneous values at the sternum (' $r$ ' value- 0.669 ). A study performed by Lucia Stillova, Katarina Matasova et al in 2007,(13) observed minimal differences between TB and TCB measured over sternum. A study in Mongolian neonates(14) measured the TB with TCB (at forehead and mid sternum) showed a strong correlation $\left(\mathrm{R}^{2}=\right.$ 0.78871 and 0.78488 , respectively). Bland-Altman plots and Bradley-Blackwood test showed no significant differences between 2 methods for the measured ranges of bilirubin. Bland-Altman plots also showed linear correlation. A decrease in correlation compared to previous studies may be because babies for the present study were selected irrespective of their skin pigmentation.

Present study also found out the correlation between TSB and TCB at different sites, forehead, sternum and pubic symphysis ( $\mathrm{r}=$ was $0.722,0.669$ and 0.591 respectively) and concluded that maximum correlation was found between TSB and TCB values at forehead. Skin is thinnest at forehead, which may be a reason for this significant correlation. This is in contrast to the above-mentioned study by Lucia Stillova et al,(13) which showed only a minimal difference of TCB values from forehead and mid sternum. Study done at Dept. of Paediatrics, Indira Gandhi Medical College, Shimla, published in Indian Paediatrics, 2005(15) and a research published in J Paediatr in 2007 April by Boo NY, Ishak S(16) showed somewhat similar correlations between TCB at forehead and sternum with TSB; ' $r$ ' values at forehead and sternum was 0.878 and 0.859 in the first study and 0.80 and 0.86 in the second study respectively. Babies were selected irrespective of skin pigmentation in the present study compared to other studies, where babies with uniform skin colour were studied.

We found a positive correlation between TCB and entire range of TSB. Maximum correlation was found for TB $<10$ (' $r$ ' value- 0.625 ). For TB $10-15$ ' $r$ ' value is 0.421 and for TB $>15$ ' $r$ ' value is 0.231 . No references were found for the decreasing correlation between the two methods with rising bilirubin levels.

Sensitivity and specificity of the study is $80.7 \%$ and $79.6 \%$, respectively. Positive predictive value is $68.6 \%$ and negative predictive value is $88.1 \%$. The sensitivity was found to be less compared to previous studies by Boo NY and Ishak et al(16) which showed sensitivity of $100 \%$ and a study done at King Edward Medical College, Lahore,(17) which showed a sensitivity of $90 \%$. In the above-mentioned study, transcutaneous readings were taken from 3 different sites 
and the mean value was taken for comparison. Thus, the present study shows that the TCB meter lacks the adequate sensitivity that is needed for a screening test compared to other studies. Specificity is almost equal in the present study and that done at King Edward Medical College, Lahore (78\%).(17)

Total Serum Bilirubin for the present study was estimated by Vandenberg method, while in other studies newer methods like spectrophotometry $(13,14,18)$ and high performance liquid chromatography was used, which may be the reason for low sensitivity of TCB in present study.

\section{CONCLUSION}

As there is a good positive correlation between TCB and TSB, transcutaneous bilirubinometer can be used as a screening tool for assessing and monitoring neonatal jaundice.

As the maximum correlation is with forehead measurement, this is the preferred site for transcutaneous bilirubinometry.

As the relationship decreases with increasing serum bilirubin level, serum bilirubin should be done for planning the management, when it reaches the phototherapy range.

\section{Limitations}

Total serum bilirubin levels were estimated by Vandenberg method, rather than spectrophotometric method and High Performance Liquid Chromatography.

Newborns were selected irrespective of the skin colour.

Other factors affecting serum bilirubin levels like albumin, free fatty acids and haematocrit were not considered.

\section{REFERENCES}

[1] Dennery PA, Seidman DS, Stevenson DK. Neonatal hyperbilirubinemia. N Engl J Med 2001;344(8):58190.

[2] American Academy of Pediatrics Subcommittee on hyperbilirubinemia. Management of hyperbilirubinemia in newborn infants more than 35 weeks of gestation. Pediatrics 2004;114(1):297-316.

[3] IP S, Chung M, Kulig J, et al. An evidence based review of important issues concerning neonatal hyperbilirubinemia. Pediatrics 2004;114(1):130-53.

[4] Paul VK, Bagga A. Ghai Essential Pediatrics. $8^{\text {th }}$ edn. CBS Publishers \& Distributors Pvt Ltd., 2013:172-3.

[5] Grohman K, Roser M, Rolinsky B, et al. Bilirubin measurement for neonates: comparison of 9 frequently used methods. Pediatrics 2006;117(4): 1174-83.
[6] Muraca M, Blanckaert N. Liquid chromatography assay and identification of mono and di-ester conjugates of bilirubin in normal serum. Clinical Chemistry 1983;29(10):1767-71.

[7] Bosschaart N. Quantitative and localised spectroscopy for non-invasive bilirubinometry in neonates. UvADARE 2012;2:108.

[8] Yap SH, Mohammed I, Ryan CA, et al. Avoiding painful blood sampling in neonates by transcutaneous bilirubinometry. Irish Journal of Medical Science 2002;171(4):188-90.

[9] Tayaba R, Gribetz D, Gribetz I, et al. Non-invasive estimation of serum bilirubin. Pediatrics 1998;102(3):e28.

[10] Maisels JM. Non-invasive measurements of bilirubin. Pediatrics 2012;129(4):779-81.

[11] Cloherty JP, Eichenwald EC, Hansen AR, et al. Manual of Neonatal Care. $7^{\text {th }}$ edn. Lippincot Williams \& Wilkins 2015:304-39.

[12] Bland JM, Altman DG. Statistical method for assessing agreement between two methods of clinical measurement. The Lancet 1986;327(8476):307-10.

[13] Stillova L, Matasova K, Mikitova T, et al. Evaluation of transcutaneous bilirubinometry in preterm infants of gestational age 32-34 weeks. Biomed Pap Med fac University Palacky Olomouc Czech Republic 2007;151(2):267-71.

[14] Akahira-Azuma M, Yonemoto N, Ganzorig B, et al. Validation of transcutaneous bilirubin meter in Mongolian neonates: comparison with total serum bilirubin. BMC Pediatrics 2013;13:151.

[15] Mahajan G, Kaushal RK, Sankhyan N, et al. Transcutaneous bilirubinometry in assessment of neonatal jaundice in Northern India. Indian Pediatr 2005;42(1):41-5.

[16] Boo NY, Ishak S. Prediction of severe hyperbilirubinemia using the Bilichek transcutaneous bilirubinaemia. J Pediatr Child Health 2007;43(4):297302.

[17] Laeeq A, Yasin M, Chaudhry AR, et al. Transcutaneous bilirubinometerry: clinical application. JPMA 1993: 28-30.

[18] Badiee Z, Mohammadizadeh M, Shamee M, et al. Diagnostic usefulness of transcutaneous bilirubinometry in very preterm newborns. International Journal of Preventive Medicine 2012;3(4):262-5. 